\title{
High Speed Rail and Tourism: Empirical evidence from Spain
}

\author{
Daniel Albalate *
}

\author{
Xavier Fageda $^{+}$
}

\begin{abstract}
Abstract: This paper evaluates how changes in the provision of high-speed rail (HSR) services affect tourism outcomes in Spain, a tourist country with the newest and longest HSR network in Europe. To do so it employs an empirical strategy based on the differences-in-differences panel data method with double fixed effects. Data are provided by Spain's National Statistics Institute (INE) and cover 50 provinces over a 15-year time span (1998-2013). Our results provide mixed evidence about the impact of HSR accessibility on tourist outcomes. On the one hand, we find that air traffic is negatively affected by HSR and air traffic is a strong predictor of tourist arrivals. This suggests a negative indirect effect of HSR on tourist outcomes. On the other hand, HSR may have a positive (weak) direct effect on tourism. However, such result is conditioned on the measure of HSR accessibility and econometric technique used. Thus, the net effect of HSR on tourism outcomes is not consistently positive. This pattern might be attributed to a network design that does not respond to ridership needs and which has a substitution effect on air transportation, the main mode for long-distance tourist mobility.
\end{abstract}

Keywords: High-Speed Rail, Tourism, Transportation, Modal Competition.

JEL Codes: H54; L83; O18; R41

\footnotetext{
* Corresponding author. Universitat de Barcelona. Departament de Política Econòmica. Av. Diagonal 690, 08034, Barcelona (Spain). Tel: +34.934031131 - email: albalate@ub.edu

+ Universitat de Barcelona. Departament de Política Econòmica. Av. Diagonal 690, 08034, Barcelona (Spain). +34.934039721 email: xfageda@ub.edu
} 


\section{High Speed Rail and Tourism: Empirical evidence from Spain}

\section{Introduction}

Transportation and tourism are closely related economic activities, so much so that promoting transportation infrastructure and guaranteeing efficient mobility are usually seen as contributing to the development of the tourism industry. As early articles have shown there is a well-established relationship between transport infrastructure and demand in the tourist sector (Chew, 1987; Martin \& Witt, 1988; Abeyratne, 1993; Khadaroo and Seetanah, 2007, 2008). Thus, transportation acts on one of the determinants of a tourist destination, i.e., it improves accessibility to a particular location (Della Corte et al., 2013) and, moreover, it plays a critical role in mobility once tourists are at their destination. It is hardly surprising therefore that a number of recommendations have been forwarded for integrating transport and tourism policies (see Scuttari et al., 2013).

However, the impact of transportation on tourism is not solely positive. As Hall (1999) claimed, tourist mobility can be critical for such social concerns as inequality and sustainability. Thus, tourism mobility can produce negative externalities, with residents and tourists competing for scarce and constrained transport supply (Albalate and Bel, 2010), and other environmental impacts including climate change, air quality, noise, and nature/landscape (Peeters, Szimba and Duijnisveld, 2007). In short, while all modes of transportation can produce both positive and negative externalities, transportation infrastructure and services can reasonably be considered allies of tourist development strategies. This point of view is typically the one adhered to by local policy makers and local actors in the tourist sector, as reflected by their frequent lobbying to receive more infrastructure and transport service supply.

All modes of transportation can be considered allies of tourism. Local transportation, for example, facilitates tourist mobility, while long-distance transportation is critical for the overall number of tourists that a destination receives, with airports being the primary gateways for tourist arrivals. However, the precise relationship of other modes of medium- and long-distance transportation with tourism has been largely overlooked in the literature. Among these modes, high-speed rail (HSR) represents a contemporary revolution in transportation technology and has been promoted in various countries around the world (Albalate and Bel, 2012). ${ }^{1}$ HSR typically has a very specific passenger orientation, hence its importance for the tourism industry, but recent studies indicate that its main impact on mobility is to substitute airline passenger volumes, rather than to induce a higher number of new trips. Given that HSR may be weakening air transportation, this as yet unidentified net effect of HSR on tourism needs to be tested.

This paper contributes to the literature by calculating the impact of the opening up of new HSR lines on tourism outcomes. This policy is examined in Spain, Europe's leader in the adoption of this transportation technology and one of the continent's main tourist destinations. The analysis is conducted at the provincial level using an econometric strategy based on the implementation of the differences-in-

\footnotetext{
${ }^{1}$ Here we understand HSR technology to refer to trains capable of reaching speeds of $\geq 250 \mathrm{~km} / \mathrm{h}$.
} 
differences panel data method. The overall aim is to test whether or not claims of positive externalities of HSR in the tourism industry are well founded.

The rest of the paper is organized as follows. In the next section, the related literature is reviewed in order to build hypotheses about the role of HSR and tourist outcomes. The development, design and characteristics of Spain's HSR network are then described. Section four outlines the empirical strategy adopted in evaluating the impact of HSR on tourism at the provincial. This is followed by a presentation and discussion of the main results. The last section offers some brief conclusions.

\section{Literature Review}

Various studies of the deployment of HSR lines and their impact have addressed this specific relationship with the tourism sector. Thus, the improved accessibility of a tourist destination is reported as being expected to revitalize urban and business tourism (Delaplace and Perrin, 2013; Bazin et al., 2010; Masson and Petiot, 2009) and promoters associate the arrival of HSR with an improvement in the attractiveness of tourist destinations and as an opportunity to renew the tourist supply (see Delaplace et al., 2014; Feliu, 2012). A number of articles have forecast gains for the tourism industry from HSR links in Amsterdam (Riietveld et al., 2001), Kent (Gibb, 1986), Anaheim and San Diego (Murakami and Cervero, 2012), Melbourne and Canberra (Edwards, 2012), and the Chinese Provinces (Chen and Haynes, 2012) among others.

The ex-post evaluation of the relationship between HSR and tourism

However, results from ex-post evaluations of the impact of HSR are far from being so enthusiastic. A sound contribution is Bazin et al. (2006), which studied the impact of new TGV services on different economic sectors in France between 1990 and 1999. They reported that the new services failed to excite much curiosity, except for a somewhat sporadic impact on initial demand as passengers tried out the service. They argued that the availability of HSR gave value to already popular tourist destinations, but that it was insufficient to promote further tourist development, and that additional policies were required to sustain the initial demand shock. Interestingly, the authors found that the number of overnight stays fell and the profile of the typical visitor changed, to the extent that a restructuring was noted in the tourist industry. Thus, in some cities small hotels with limited services disappeared, while France's large national chains increased their offer and enhanced their quality to satisfy the demands of business tourism. The impact of HSR on leisure tourism appeared to be much more limited, and several projects developed on the basis of increased visitor numbers had to be abandoned (see Bazin et al., 2006, for specific examples).

City size appears to be an important determinant of the impact of HSR on tourism (Delaplace, 2012b). Thus, Bazin et al. (2013) reported that the increase in the number of tourists attributable to a new HSR service was minimal in many small and medium-sized European cities, although positive effects were detected in intermediate cities pre-equipped with tourist amenities. SEEDA (2008) also examined HSR impacts on thirteen cities in Germany, the Netherlands, the United Kingdom and France and found that 
only a few cities experienced a revitalization of their tourist industries. In contrast, evidence from Asia points in the opposite direction. This is the case in Japan (Okabe, 1979), Taiwan (Cheng, 2009) and China (Wang et al., 2012; Chen and Haynes, 2012).

A recent study by Pagliara et al. (2015) have evaluated the impact of Madrid's HSR on tourist destination choice. Their results, which are closely associated with the findings reported herein, suggest that HSR is not a key determinant of tourists' choice of destination since the majority are international tourists arriving by air. However, Madrid's HSR appears to be attractive to international tourists when visiting nearby towns and cities. A similar conclusion is reached by Chen and Haynes (2015) in their study of the impact of Chinese HSR systems on international tourism demand. They find a small demand elasticity (0.057) with respect to an HSR station on international tourism arrivals. However, when the railway network density is included a larger impact is recorded.

\section{The substitution effect between HSR and other modes of transportation}

Bolstering tourism with transportation is only of any relevance when it increases the overall number of users or the number of a given type of visitor (high income, long-stay tourists, etc.). However, if HSR is unable to generate new journeys and so increase demand in the sector, it merely takes on a predatory role as it competes with other modes of transportation. There is a growing body of literature examining the modal competition between HSR and air transportation (see Givoni and Dobruszkes, 2013, for a review) that stresses the former's ability to attract a relatively large market share of medium-distance travelers. This market share gain is won mainly at the expense of the airline industry. As a result, HSR has become a major determinant of market power loss (Zhang et al., 2014) and a major barrier to entry for airlines (Kappes and Merkert, 2013).

The interaction between airlines and HSR is of essential importance in any analysis of the impact of the latter on tourism given that airports are the main gateways for tourists and air transportation is the chief mode for long-distance mobility. Furthermore, the relationship between air transportation and tourism has been well established in the literature (see Bieger and Wittmer, 2006; Dobruszkes and Mondou, 2013, among others). In this regard, some recent studies provide evidence about the strong effect that low-cost airlines have on tourist outcomes (Donzelli, 2010; Chung and Wang, 2011; Rey et al., 2011)

If we consider HSR as being able to compete with airlines over distances under $700 \mathrm{~km}$ and as being faster than conventional rail and road over distances of more than $200 \mathrm{~km}$, then there is a significant range within which HSR substitution effects can occur. In Spain, since most HSR connections lie within this range, we would expect a marked substitution effect with the introduction of new lines and the undermining of air transportation.

Evidence of sizeable losses in airline market shares and reductions in airline operations due to the opening up of HSR lines are documented for all countries with high speed lines. The substitution effect is well documented from the pioneering inaugurations of HSR lines in Japan and continuing network developments (Taniguchi, 1992; Clever and Hansen, 2008; Albalate and Bel, 2012; Fu et al., 2014) in the European pioneering state, France (Bonnafous, 1987; European Commission, 1996; Vickerman, 1997; 
Klein, 1997) and in other European countries, including: Spain (European Commission, 1996; Román et al., 2007; Martín and Nombela, 2008; Jiménez and Betancor, 2012; Pagliara, Vassallo and Román, 2012), Italy (Cascetta et al., 2011) and Germany (Ellwanger and Wilckens, 1993; Dobruszkes, 2011). Dobruszkes, Givoni and Dehon (2014) and Albalate, Bel and Fageda (2015) also show this substitution effect using various econometric techniques and for a sample of European routes. Similar impacts on air transportation have been documented in Asia, including Korea (Suh, Yang and Kim, 2005; Lee, Yo and Jung, 2012), China (Fu, Zhang and Lei, 2012; Wu 2013) and Taiwan (Yung-Hsiang Cheng, 2010).

Despite the foregoing, Steer Davies Gleave (2006) recognizes that competition between HSR and air transportation is not so straightforward when the air routes are operated by low-cost carriers. Similarly, Beherens and Pels (2012) show that while HSR is a competitor for both conventional and low-cost carriers, some conventional airlines subsequently pulled out of the London-Paris market. Indeed, the airline industry in Japan has only been able to grow with the appearance of low-cost carriers following air transport liberalization (Albalate and Bel, 2012).

In contrast to the above studies that have identified a substitution effect, a number of articles focus on the possible complementarities between modes (see Givoni and Banister, 2006). Dobruszkes (2011) finds that the flag carrier airline Lufthansa increased its services after the entry into service of the CologneFrankfurt HSR line. ${ }^{2}$ This showed that under certain circumstances HSR could complement rather than substitute air transportation. Dobruszkes, Dehon and Givoni (2014) also found complementarities in hubbing strategies led by the airlines. Likewise, Albalate, Bel and Fageda (2015) found some room for complementarities where HSR services have stations located within hub airports, since in such instances HSR could feed air demand. In contrast, Dobruszkes, Dehon and Givoni (2014) were unable to find any statistical support for airline/HSR integration at airport stations. Overall, in the European markets considered, the main relationship detected between HSR and air services is that of substitution. Albalate, Bel and Fageda (2015) show that airlines subject to competition from HSR reduce the number of seats made available on the route, while flight frequencies are not always subject to any reduction. In contrast, Dobruszkes, Dehon and Givoni (2014) found reductions on both seats and flights.

If we extend our analysis beyond the impact on air transportation and airports (which appear to be the main gateway for tourists), HSR is also found to substitute conventional rail services (typified by a higher number of stops and cheaper tickets). This substitution effect is usually triggered by rail service managers themselves as they seek to increase the occupancy rate of high-speed trains. As a result, it is not usual to see conventional and regional services being dismantled, as HSR is established as a node-to-node transportation mode, serving the main urban agglomerations. This process creates a tunnel effect, with the degradation of areas not served by the new HSR services, and a suction effect, as the main network nodes attract economic activity away from the smaller, less dynamic nodes. In studying the effect of HSR on tourism we need, therefore, to consider whether the tourist activity attracted - if any - is new or simply activity attracted from other locations that have seen a deterioration in their accessibility.

\footnotetext{
${ }^{2}$ However, the airline was later forced to reduce flight frequencies with the entry into service of the Cologne-Munich HSR line, despite the fact that this service includes a number of stops and does not cover the whole trajectory at high speed.
} 


\section{High-Speed Rail in Spain}

According to the International Union of Railways (UIC), Spain ranks second only to China in terms of the length of its HSR network, and first if we correct figures by population. It is the clear leader in Europe and HSR has been and remains the main transportation development project. However, this situation contrasts markedly with HSR ridership (number of trips) figures, which show that ridership is much higher in France, Germany and Italy despite their more limited networks. While ridership in Japan is well over 300 million, and over 110 million in France, the number of trips on the Spanish HSR network in 2014 was below 30 million. If we consider the intensity of network use (passenger-km per $\mathrm{km}$ of network), the ridership in France is five times greater than in Spain, while in Germany and Italy it is 4.4 and 2.6 times greater, respectively (Albalate, Bel and Fageda, 2015). Indeed, current figures are likely to show even greater divergences as low density HSR lines have been opened up in Spain, while the economic crisis has reduced demand across the whole network.

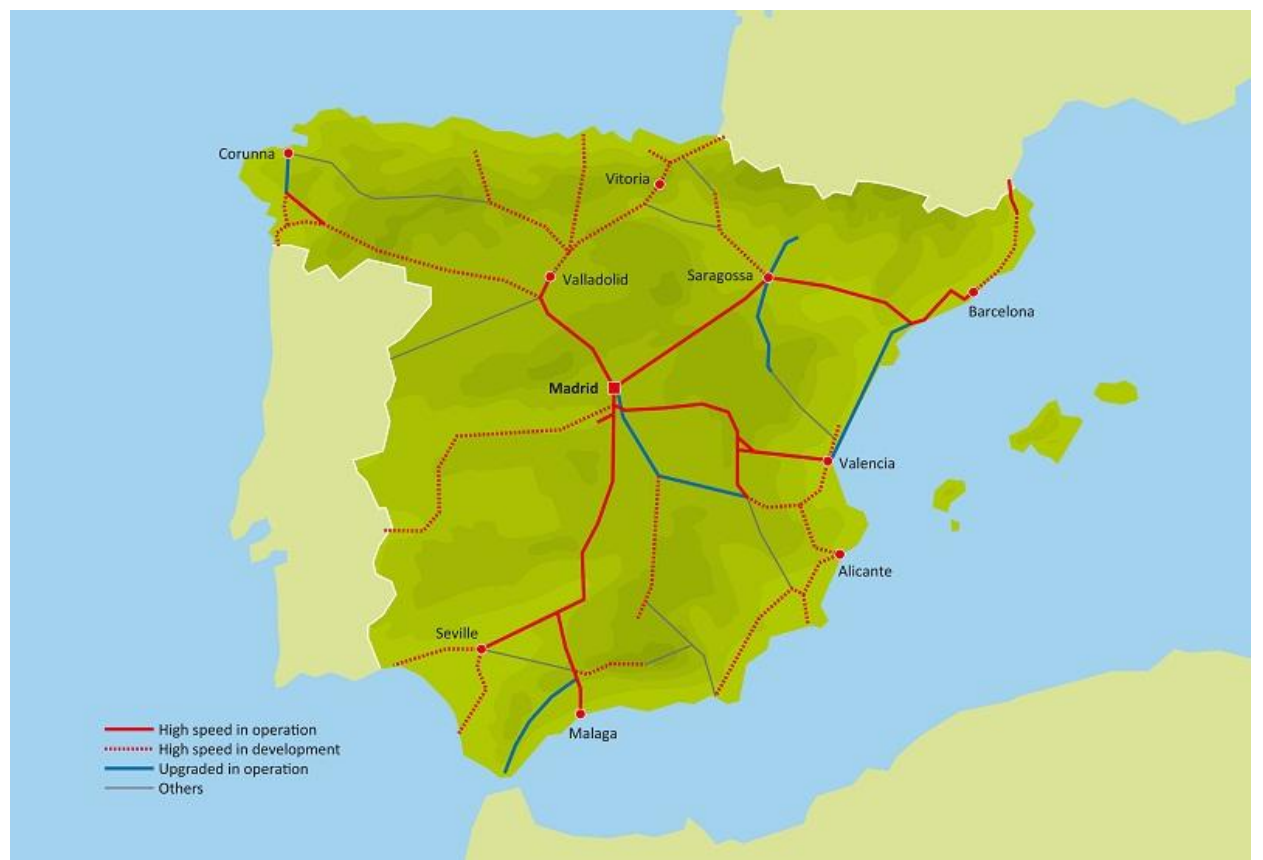

Figure 1. Spanish High Speed Rail network, 2014.

Source: International Union of Railways, UIC

This contrast between supply and demand highlights the fact that Spain's transport policy has not been governed by goals of efficiency, but rather on providing this new technology to all provincial capitals with the aim of connecting them to Madrid in the shortest possible time (Bel, 2011; 2012). The network structure illustrated in Figure 1 gives priority to connections between Madrid and the periphery as opposed to developing the country's transversal corridors, i.e., linking the tourist enclaves along the Mediterranean and Cantabrian Seas to the east and north of Spain, respectively. Albalate, Bel and Fageda (2012) have shown empirically that centralization has been the clear driver of transportation investments in network modes (railways and roads) in Spain, while mobility needs have been relegated to a secondary plane. For this motive, Spain represents an interesting case study as it does not suffer from any selection bias that might arise from the fact of building HSR services in the country's main tourist locations. 
Within this context, Figure 2 shows the evolution of tourist arrivals and the number of provinces with HSR stations in Spain using data obtained from the Spain's National Statistics Institute (INE) and from the Spain's Administrator of Railway Infrastructure (ADIF). It can be seen a steady growth of tourism in Spain, so that the numbers of tourists have almost doubled in the considered period. In a similar vein, an increasing number of provinces have HSR stations since 2003. Note here that the expansion of the HSR network is particularly important in the period that coincides with the economic and financial crisis.

Figure 2. Evolution of tourist arrivals and number of provinces with high-speed rail stations

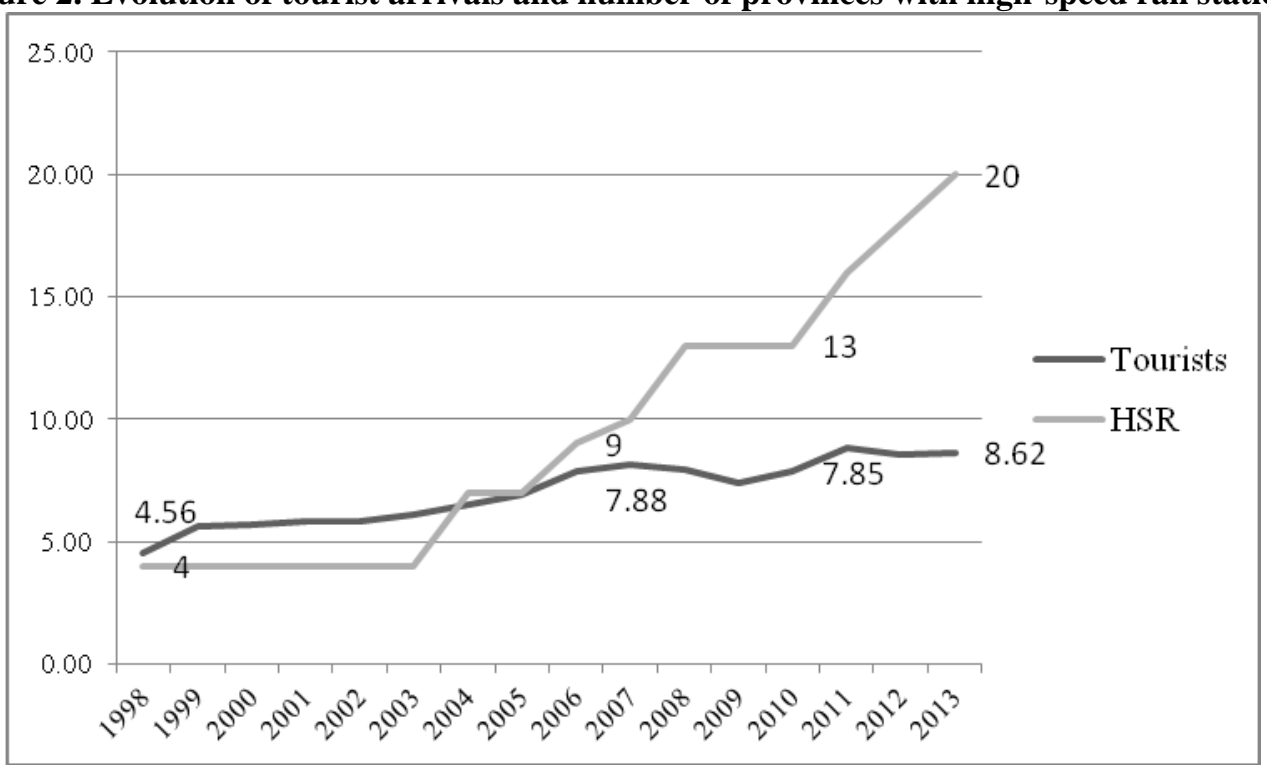

Note: Tourist arrivals are measured in terms of dozens of millions to make easier the comparison with number of provinces with high-speed rail stations

Source: Spain's National Statistics Institute (INE) and Spain's Administrator of Railway Infrastructure (ADIF).

In a similar vein, Table 1 shows the mean comparison tests of tourist arrivals for provinces that have gained access to the HSR in the considered period. It can be seen that most of these provinces have more tourists after the launching of the new HSR station. Thus, this table provides some descriptive evidence in favor of the hypothesis that HSR have promoted tourism. However, these tests present a rough picture of the effect of HSR on tourism as we must control for other explanatory factors.

Table 1. Tourist arrivals before and after having a high-speed rail station (mean comparison tests)

\begin{tabular}{|c|c|c|c|c|}
\hline Province & $\begin{array}{c}\text { First year with } \\
\text { HSR station }\end{array}$ & $\begin{array}{c}\text { Tourists before } \\
\text { HSR station }\end{array}$ & $\begin{array}{c}\text { Tourists after } \\
\text { HSR station }\end{array}$ & $\begin{array}{c}\text { T-test (Ho: No } \\
\text { mean } \\
\text { differences) }\end{array}$ \\
\hline A Coruña & 2012 & 13.85 & 14.5 & -0.29 \\
\hline Albacete & 2011 & 2.92 & 3 & -0.46 \\
\hline Barcelona & 2008 & 60.5 & 93.13 & $-5.91^{* * *}$ \\
\hline Cuenca & 2011 & 3 & 3 & 0.00 \\
\hline Guadalajara & 2004 & 2 & 2.6 & $-2.80^{* *}$ \\
\hline Huesca & 2006 & 5.62 & 7 & $-5.22^{* * *}$ \\
\hline Lleida & 2004 & 6.83 & 7.8 & $-4.49^{* * *}$ \\
\hline Málaga & 2008 & 36.1 & 44 & $-2.71^{* *}$ \\
\hline Ourense & 2012 & 2.57 & 3 & -0.91 \\
\hline Tarragona & 2007 & 16.55 & 23 & $-3.38^{* * *}$ \\
\hline Toledo & 2006 & 5.87 & 7 & $9.00^{* * *}$ \\
\hline Valencia & 2011 & 19.84 & 26 & $-6.15^{* * *}$ \\
\hline Valladolid & 2008 & 4.9 & 6 & $-3.03^{* *}$ \\
\hline
\end{tabular}




\begin{tabular}{|c|c|c|c|c|}
\hline Zaragoza & 2004 & 9.16 & 11.1 & $-3.53 * * *$ \\
\hline
\end{tabular}

In particular, air traffic in Spain has grown dramatically in recent years. According to data of the Spanish airport operator (AENA), Spanish airports moved 120 million passengers in 1998 while they moved 190 million in 2013 with a peak of 210 million passengers in 2007. Such increase can be attributed almost exclusively to low-cost airlines. Indeed, table 2 depicts the evolution of total flights and the share of lowcost airlines in Spanish airports in terms of such departures using information provided by RDC aviation. Data in this table show that the increase in the total number of flights has been about $18 \%$. In contrast, the increase in the total number of flights channeled by low-cost airlines has been about $400 \%$. Their share in Spanish airports has grown from $12 \%$ to $50 \%$ (table A1 in the appendix provides the list of low-cost airlines considered). As it is shown in table 2, the leading low-cost airlines in Spain are currently Ryanair and Vueling which have several operating bases in the Spanish airport network.

Table 2. Evolution of total flights (departures) and share of low-cost airlines in Spanish airports

\begin{tabular}{|c|c|c|c|c|c|c|}
\hline Year & $\begin{array}{c}\text { Total } \\
\text { departures }\end{array}$ & $\begin{array}{c}\text { Share of low-cost } \\
\text { airlines }\end{array}$ & Ryanair & Vueling & Easyjet & $\begin{array}{c}\text { Air } \\
\text { Berlin }\end{array}$ \\
\hline 2002 & 594,685 & $12 \%$ & $0 \%$ & - & $2 \%$ & $2 \%$ \\
\hline 2003 & 632,247 & $15 \%$ & $1 \%$ & - & $3 \%$ & $3 \%$ \\
\hline 2004 & 681,641 & $18 \%$ & $2 \%$ & $0.01 \%$ & $3 \%$ & $3 \%$ \\
\hline 2005 & 780,861 & $21 \%$ & $3 \%$ & $2 \%$ & $3 \%$ & $5 \%$ \\
\hline 2006 & 845,704 & $23 \%$ & $3 \%$ & $3 \%$ & $3 \%$ & $5 \%$ \\
\hline 2007 & 935,927 & $28 \%$ & $4 \%$ & $3 \%$ & $4 \%$ & $4 \%$ \\
\hline 2008 & 917,666 & $30 \%$ & $6 \%$ & $4 \%$ & $5 \%$ & $5 \%$ \\
\hline 2009 & 850,139 & $34 \%$ & $8 \%$ & $7 \%$ & $5 \%$ & $5 \%$ \\
\hline 2010 & 824,205 & $38 \%$ & $11 \%$ & $8 \%$ & $5 \%$ & $5 \%$ \\
\hline 2011 & 845,290 & $41 \%$ & $14 \%$ & $8 \%$ & $5 \%$ & $4 \%$ \\
\hline 2012 & 770,223 & $47 \%$ & $16 \%$ & $10 \%$ & $6 \%$ & $4 \%$ \\
\hline 2013 & 701,905 & $50 \%$ & $16 \%$ & $12 \%$ & $6 \%$ & $4 \%$ \\
\hline
\end{tabular}

Note 1: Shares of airlines are measured in terms of total departures.

Note 2: Data are only available for the period 2002-2013.

Note 3: The rest of low-cost airlines have individually a share lower than $1 \%$ in all years of the considered period (with the exception of Clickair that was a low-cost subsidiary of Iberia).

Source: RDC aviation (capstats statistics)

Overall, Spain is a good case study to examine the effect of two recent innovations in transportation on tourism outcomes. HSR can be considered a technological innovation and the low-cost airline business model can be considered a managerial innovation. While we put the attention on the technological innovation that HSR represents, air traffic must be also included in the empirical analysis to have a more accurate view of the net effect of HSR on tourism outcomes.

\section{Empirical strategy}

We evaluate how HSR impacts on two tourism outcome variables: the total number of tourists (visitors) and the mean duration of their stays (number of overnights). We draw on tourism data provided by Spain's National Statistics Institute (INE) that covers 50 provinces with a 15-year time span (19982013). ${ }^{3}$ Hence, we have a sample with 750 observations. The method chosen is a slight extension of the

\footnotetext{
${ }^{3}$ The autonomous cities of Ceuta and Melilla in Africa are not included.
} 
differences-in-differences estimation procedure specified as a two-way fixed effects model that takes the following form:

$$
Y_{p t}^{i}=X_{p t} \beta+\delta Z_{p t}+w_{p}+v_{t}+\varepsilon_{p t}
$$

where $Y_{p t}^{i}$ is the dependent variable (tourism outcome $\mathrm{i}$, in province $\mathrm{p}$, in period $\mathrm{t}$ ), $X_{p t}$ contains the vector of time-varying control covariates, and $Z_{p t}$ is the policy dummy variable to be evaluated - in this case, the availability of HSR services $\left(\mathrm{D}^{\mathrm{HSR}}\right)$ or the number of HSR destinations (HSR_dest). As usual, $w_{p}$ and $v_{t}$ are province-specific and year-specific fixed effects and $\varepsilon_{p t}$ is a mean-zero random error. Province fixed effects control for time-invariant province-specific omitted variables and year dummies control for province trends. The key element in this differences-in-differences model is the parameter $\delta$, which measures the difference between the average change in tourism outcomes for provinces with HSR availability and the average change in those provinces without HSR.

Specifically,

$$
\delta=\left[E\left(Y_{A} / G=1\right)-E\left(Y_{B} / G=1\right)\right]-\left[E\left(Y_{A} / G=0\right)-E\left(Y_{B} / G=0\right)\right]
$$

where $Y_{B}$ and $Y_{A}$ denote tourism outcomes before and after HSR inauguration and $G=1$ and $G=0$ denote the treatment (provinces with HSR services) and control (provinces without HSR services) group observations, respectively.

Descriptive statistics for the variables included in model (1) are provided in Table 3. Two different dependent variables are included: the total number of tourists and the average number of overnight stays per tourist. Two policy variables are employed that consequently produce different specifications and evaluation outcomes. First, the impact of HSR is evaluated using a binary variable that takes a value of 1 if HSR is available in the province and 0 otherwise. Second, a discrete variable is used to identify the number of HSR destinations available from any given HSR node. Note that several variables that are used in the empirical analysis as dependent variables (tourists, overnights, airport traffic) have a standard deviation larger than the mean. This may indicate that such variables are not normally distributed which must be addressed in the empirical analysis.

Note that following a standard transport economics rationale the variable of interest could be considered as being simultaneously determined by the number of tourists. Indeed, transportation policy could be designed so as to supply services and accessibility according to demand. Tourism would be a credible source of such demand, pointing to a problematic inverse causal relationship between the dependent and treatment variables. However, as explained in the previous section, transportation policy in Spain (especially with regard to HSR service endowments) bears no relationship with tourist activities. Indeed, the government policy has been to connect all the provincial capitals to Madrid, regardless of the demand 
in these corridors and tourism has never been officially recognized as a driver of HSR investment. This offers an appropriate source of identification.

Table 3. Descriptive statistics for dependent and explanatory variables.

\begin{tabular}{|c|c|c|c|c|c|}
\hline Variable & Description & Mean & Std. Dev. & Min & Max \\
\hline Tourists & $\begin{array}{l}\text { Number of tourists (visitors - } \\
\text { hundreds of thousands) }\end{array}$ & 14.02 & 18.07 & 1 & 104 \\
\hline Overnights & $\begin{array}{l}\text { Nights spent in tourist installations } \\
\text { (nights - hundreds of thousands) }\end{array}$ & 49.63 & 88.31 & 2 & 587 \\
\hline $\mathrm{D}^{\mathrm{HSR}}$ & $\begin{array}{l}\text { Binary variable taking value } 1 \text { if } \\
\text { HSR is available, } 0 \text { otherwise }\end{array}$ & 0.19 & 0.39 & 0 & 1 \\
\hline HSR_dest & $\begin{array}{l}\text { Number of HSR destinations } \\
\text { accessible from HSR station }\end{array}$ & 0.72 & 1.78 & 0 & 15 \\
\hline Airport_traffic & $\begin{array}{c}\text { Number of passengers (hundreds of } \\
\text { thousands) }\end{array}$ & 34.19 & 83.16 & 0 & 521 \\
\hline Population & Inhabitants (hundreds of thousands) & 8.78 & 10.75 & 1 & 65 \\
\hline Unemployment & $\%$ of unemployed in the province & 14.62 & 7.65 & 3 & 42 \\
\hline Rainfall & $\begin{array}{l}\text { Milliliters of rain recorded at the } \\
\text { province's control station }\end{array}$ & 554.14 & 324.56 & 64 & 2450 \\
\hline $\mathrm{D}^{\text {hub }}$ & $\begin{array}{l}\text { Binary variable taking value } 1 \text { if } \\
\text { airports is a hub of a network carrier }\end{array}$ & 0.03 & 0.17 & 0 & 1 \\
\hline $\begin{array}{l}\text { Gross domestic } \\
\text { product }\end{array}$ & Euros of 2005 (millions) & 17.10 & 26.52 & 1.46 & 179.75 \\
\hline Low_cost & $\begin{array}{c}\text { Number of operating bases of low- } \\
\text { cost airlines }\end{array}$ & 0.15 & 0.46 & 0 & 3 \\
\hline Airport_enlargament & $\begin{array}{l}\text { Binary variable taking value } 1 \text { if } \\
\text { new terminal is working, } 0 \\
\text { otherwise }\end{array}$ & 0.03 & 0.16 & 0 & 1 \\
\hline
\end{tabular}

Beyond these policy variables, several groups of explanatory variables are controlled for here. First, time varying provincial characteristics that can affect the growth of tourism are considered. Thus, province size is introduced by including the total number of inhabitants (population), given that the total number of tourists is the dependent variable. Moreover, changes in the weather over time are controlled for by including annual precipitation (rainfall) and changes in the economic cycle are taken into consideration by including the unemployment rate of the province. Features of the climate and weather (Lise and Tol, 2002; Gómez, 2005; Day et al., 2013) and economic cycle characteristics (Bramwell and Lane, 2009; Guizzardi and Mazzocchi, 2010; Alegre, Mateo and Pou, 2013) are well-known determinants of tourism demand. Note also that the major expansion of the HSR network in Spain has taken place during the last years of the considered period that are characterized by a deep economic crisis that dramatically increase levels of unemployment. Hence, the variable of unemployment rate may also control for the simultaneous development of the HSR network and the economic crisis in Spain. Otherwise, the effect of climatic variables may be already captured by the province and time fixed effects as our estimation is not able to capture the long-term impact of weather on tourism.

We also include as explanatory variable traffic moved by airports of the province. As we mention above, the relationship between air transportation and tourism has been well established. Furthermore, this variable will allow us to capture more appropriately the impact of HSR on tourism outcomes. On the one hand, HSR may improve the accessibility of the province by surface transportation modes. Hence, we may expect a positive direct effect of HSR on tourism. On the other hand, HSR may have a negative 
effect on air traffic in the province. Thus, we may expect a negative indirect effect of HSR on tourism as air traffic should be a strong predictor of tourist outcomes.

Unfortunately, data about rail traffic are very limited as they usually cover few years and are not available at the province level. Thus, we are not able to quantify the impact of HSR on the total traffic volume in the province.

Taking this into account, we report the results of an additional regression that must be seen as an ancillary regression to the main equation (1) which is the basis of the empirical analysis. In such ancillary regression, we consider as dependent variable air traffic in the province and we include a variable for HSR accessibility as explanatory variable. Here, we can examine the impact of HSR on air traffic in the province. Furthermore, this regression will provide us instruments for the airport traffic variable in the tourism equation. Indeed, we need to address the potential endogeneity bias due to the simultaneous determination of air traffic and tourism

As explanatory variables of airport traffic, we include two variables related with the economic performance of the province; the gross domestic product and the unemployment rate. We also consider several variables related with the dynamics of the air transport market in Spain. In this regard, we consider a binary variable that takes value 1 for hub airports. By definition, hub airports are those airports in which a dominant network carrier exploits the transfer traffic through coordinated banks of arrivals and departures. In Spain hub airports are Madrid, and Barcelona until 2006. In Barcelona, the traffic of the former Spanish flag carrier has been progressively substituted by low-cost airlines.

We also consider a variable that accounts for the number of operating basis of low-cost airlines. An operating base by a low-cost airline is an airport at which the airline permanently bases aircraft and crew. Both fleet and personnel return to the base at the end of the day. Note here that low-cost airlines tend to concentrate traffic in their operating bases. Vueling and Ryanair has several bases in Spain, while Easyjet had a base in Madrid from 2007-20012 and Air Berlin has a base in Palma de Mallorca since 2005. Finally, we include a binary variable that takes value 1 when a new terminal is working. This variable accounts for the capacity expansion in Madrid (2006), Barcelona (2009), Málaga (2010) and Alicante (2011).

Finally, time fixed effects are considered in addition to province fixed effects, omitting the initial year from the time span, i.e., 1998, which acts as a benchmark for the coefficients attached to all remaining year-specific binary variables. As discussed above, this strategy allows us to account for all factors that have a common influence on the tourism outcomes of the provinces, but which can change over time. Additionally, it allows us to account for year-specific shocks not considered in the group of controls or other simultaneous policies. 
Note that the differences-in-differences method assumes that a counterfactual is estimated by considering the change in the outcome variable for the control group and the expected change recorded by the treated group if treatment had not occurred. However, for this assumption to be valid it is necessary to demonstrate that the temporal effect in the two groups of provinces (treated and controls) is the same in the absence of HSR. A simple strategy for verifying this assumption is to estimate the equality between average changes in the two groups in the absence of intervention (see Galiani, Gertler and Schargrodsky, 2005). Here, the equality between average changes in the two groups in the pretreatment period is tested for in order to assess the plausibility of the fundamental identifying assumption. The strategy involves considering only the pretreatment years in each treated province, excluding observations from the treated years, in addition to the observations from each control province for the whole time span. Equation 1 can now be estimated, but the time dummies for the treatment and control provinces are dealt with separately because this enables us to determine whether the time trends in the pretreatment period are the same. The HSR binary variable is also dropped from the equation. The results for this test confirm that we cannot statistically reject the hypothesis of having the same time trends in the pretreatment period for the control and treatment groups. This ensures that the differences-in-differences method is an appropriate method.

\section{Results}

We use three different econometric techniques in our estimates. Because the method of differences-indifferences in panel data with long time spans can be misleading in the presence of serial correlation (Bertrand, Duflo and Mullainhatan, 2004), we follow two different strategies to deal with the autocorrelation of the residuals. First, we use standard errors clustered by province. This solution to the autocorrelation problem is based on exploiting the variation across the 50 provinces to estimate each element of the variance-covariance matrix. The estimation of this unrestricted variance-covariance matrix is consistent to heteroskedasticity and any correlation pattern within provinces over time. Second, we consider explicitly an AR (1) process in the error term. This solution to the autocorrelation problem is based on specifying an AR (1) process as the autocorrelation structure for the error term, estimate its parameters, and use these parameters to compute the standard errors.

Bertrand, Duflo and Mullainhatan (2004) use Monte Carlo simulations to examine how these alternative approaches help solve this serial correlation problem. They show that parametric corrections which estimate specific data generating processes (such as an $\mathrm{AR}(1)$ ) performs poorly given the downward bias in the estimator of the autocorrelation and a potential misspecification of the autocorrelation process. The use of an unrestricted variance-covariance matrix performs well when the number of groups is large (e.g., 50 provinces) which is our case. A clear advantage of the latter solution to the autocorrelation problem is that it uses the variation provided by the large number of provinces to estimate the autocorrelation process in a more flexible fashion. Thus, we are more confident with the results that use standard errors clustered by province. 
Furthermore, we use a generalized linear model with a gamma distribution. Recall that several variables that are used in the empirical analysis as dependent variables have a standard deviation larger than the mean which may indicate that such variables are not normally distributed. The non-normality of the dependent variable may produce substantial bias in the estimation if it is not corrected. This is especially the case when the sample size is small. Taking this into account, the technique which is considered to be more helpful to deal with this situation is the generalized linear model (GLM) using the gamma distribution. This latter technique is generally used in regressions with a continuous dependent variable with non-negative values and that it is not normally distributed as it is the case of our dependent variables. Note here that count data models (negative binominal, poisson) cannot be used when the dependent variable is continuous.

We report the results of this latter technique to examine any potential bias that could impose the nonnormality of the dependent variable. However, our sample is relatively large so that we do not expect that the non-normality distribution of the dependent variables generate a substantial bias in the estimation. Otherwise, this technique is not able to correct for the autocorrelation of the error term which in the context of our data could be more problematic.

The econometric results of the impact of HSR on air traffic at the provincial level are presented in Table 4. Note that the fixed effects (and the hub variable when using the binary variable for the availability of HSR in the province) are excluded in regressions that use the GLM with a gamma distribution due to convergence requirements of the model. The inclusion of country fixed effects implies that the estimation focuses on the within variation of the data. Hence, the coefficients in the regression that uses the GLM with a gamma distribution are not strictly comparable to the coefficients obtained in the other two regressions that use fixed effects.

A clear advantage of the fixed effects model is that it allows us to control for any omitted variables that correlate with the variables of interest and which do not change over time. Hence, the regression that uses the gamma distribution is less reliable than the regressions with the other two techniques. Having said this, the sign and statistical significance of the HSR variables are not affected by the use of one or another technique.

Indeed, it can be seen that HSR had a detrimental impact on air traffic in the provinces of Spain in which the former mode of transportation was introduced. This result is consistent across the two different variables that account for HSR accessibility. It is also consistent across the three different techniques used.

Interestingly, low-cost airlines seem to have a positive and statistically significant effect on airport traffic. In this regard, the binary variable for hubs is negative and statistically significant (except in the regression that uses the gamma distribution in which can be identified) and the variable for the number of operating bases of low-cost airlines is positive and statistically significant in all regressions. 
Table 4.

Least squares estimates for the double fixed effects equation. Airport traffic

\begin{tabular}{|c|c|c|c|c|c|c|}
\hline & \multicolumn{2}{|c|}{ FE with clusters (1) } & \multicolumn{2}{|c|}{ FE with AR-1 (2) } & \multicolumn{2}{|c|}{$\begin{array}{l}\text { GLM with gamma } \\
\text { distribution (3) }\end{array}$} \\
\hline $\mathrm{D}^{\mathrm{HSR}}$ & $\begin{array}{c}-4.29 \\
(1.70)^{* * *}\end{array}$ & - & $\begin{array}{c}-1.76 \\
(0.39) * * *\end{array}$ & - & $\begin{array}{c}-9.09 \\
(0.86)^{* * *}\end{array}$ & - \\
\hline HSR_dest & - & $\begin{array}{c}-1.72 \\
(0.76)^{* * *} \\
\end{array}$ & - & $\begin{array}{c}-1.59 \\
(0.35)^{* * * *}\end{array}$ & - & $\begin{array}{c}-1.99 \\
(0.01)^{* * *}\end{array}$ \\
\hline $\begin{array}{l}\text { Gross domestic } \\
\text { product }\end{array}$ & $\begin{array}{c}2.73 \\
(0.17) * * *\end{array}$ & $\begin{array}{c}2.87 \\
(0.22)^{* * * *}\end{array}$ & $\begin{array}{c}2.98 \\
(0.19) * * *\end{array}$ & $\begin{array}{c}3.14 \\
(0.19)^{* * *}\end{array}$ & $\begin{array}{c}1.12 \\
(0.11)^{* * *}\end{array}$ & $\begin{array}{c}1.14 \\
(0.06)^{* * *}\end{array}$ \\
\hline Unemployment & $\begin{array}{c}0.11 \\
(0.15)\end{array}$ & $\begin{array}{c}0.12 \\
(0.15)\end{array}$ & $\begin{array}{l}-0.05 \\
(0.11)\end{array}$ & $\begin{array}{l}-0.06 \\
(0.10)\end{array}$ & $\begin{array}{c}0.06 \\
(0.006)^{* * *}\end{array}$ & $\begin{array}{c}-0.03 \\
(0.002)^{* * *}\end{array}$ \\
\hline Low_cost & $\begin{array}{c}7.76 \\
(2.99) * * *\end{array}$ & $\begin{array}{c}7.98 \\
(3.02) * * *\end{array}$ & $\begin{array}{c}8.13 \\
(1.10)^{* * *}\end{array}$ & $\begin{array}{c}8.23 \\
(1.08) * * *\end{array}$ & $\begin{array}{c}59.00 \\
(24.70) * * *\end{array}$ & $\begin{array}{c}55.01 \\
(22.43)^{* * *}\end{array}$ \\
\hline Airport_enlargement & $\begin{array}{c}4.47 \\
(6.87) \\
\end{array}$ & $\begin{array}{c}7.03 \\
(7.92) \\
\end{array}$ & $\begin{array}{l}-2.25 \\
(2.83) \\
\end{array}$ & $\begin{array}{l}-0.99 \\
(2.81) \\
\end{array}$ & $\begin{array}{c}79.67 \\
(173.35) \\
\end{array}$ & $\begin{array}{c}11.84 \\
(126.94) \\
\end{array}$ \\
\hline hub & $\begin{array}{c}-30.79 \\
(3.48) * * *\end{array}$ & $\begin{array}{c}-29.39 \\
(3.69) * * *\end{array}$ & $\begin{array}{c}-24.02 \\
(5.31)^{* * * *}\end{array}$ & $\begin{array}{c}-24.60 \\
(5.21)^{* * *}\end{array}$ & - & $\begin{array}{c}136.82 \\
(161.53)\end{array}$ \\
\hline Time fixed effects & YES & YES & YES & YES & YES & YES \\
\hline $\begin{array}{c}\mathrm{R}^{2} \\
\text { Test } \mathrm{F} \text { joint } \\
\text { significance }\end{array}$ & $\begin{array}{c}0.67 \\
195.96^{* * *}\end{array}$ & $\begin{array}{c}0.68 \\
203.54 * * *\end{array}$ & $\begin{array}{c}0.68 \\
29.78 * * *\end{array}$ & $\begin{array}{l}0.68 * * * \\
32.44 * * *\end{array}$ & $\begin{array}{c}- \\
9.56 \mathrm{e}+09 * * *\end{array}$ & $\begin{array}{c}- \\
1.45 \mathrm{e}+17\end{array}$ \\
\hline $\begin{array}{l}\text { Number of } \\
\text { observations }\end{array}$ & 750 & 750 & 750 & 750 & 750 & 750 \\
\hline
\end{tabular}

Note: Standard errors in parentheses (Robust to heteroskedasticity) and clustered by province Significance at 1\% (***), $5 \%$ (**), 10\% (*). Note 2: Fixed effects (and hub variable) are excluded in regressions with gamma distribution due to convergence requirements of the model.

The econometric results of the impact of HSR on tourism at the provincial level are presented in Table 5. We use the same econometric techniques as in the airport traffic equation. Here the convergence requirements of the model does not prevent from using fixed effects in the regression that uses GLM with a gamma distribution. Additionally, we use an instrumental variables procedure to deal with the potential endogeneity of the airport traffic variable.

Airport traffic is a major determinant of tourist outcomes. This result is consistent across all the techniques used. Thus, we find evidence of a negative indirect effect of HSR on tourism. On the one hand, HSR has a detrimental impact on airport traffic. On the other hand, airport traffic is a strong predictor of tourism. Note here that the increasing presence of low-cost airlines in Spanish airports may have strengthened the relationship between air traffic and tourism in the last years.

Controlling for airport traffic, we find weak evidence in favor of the hypothesis that HSR has had a positive direct effect on tourism. Results of HSR variables are conditioned on the econometric technique used. The binary variable for HSR is positive but not statistically significant except in the regression that uses the generalized linear model with a gamma distribution in which it is negative and not statistically significant. The variable of number of HSR destinations is positive but not statistically significant in the regression that use clusters, while it is positive and statistically significant at the $10 \%$ level in the regressions that assume and $\mathrm{AR}(1)$ process in the error term and in the instrumental variables regression. In contrast, it is negative and not statistically significant in the regression that uses the generalized linear model with a gamma distribution. 
Overall, the net impact of HSR on tourism does not seem to be consistently positive. Following the inauguration of HSR services, the airlines reduced their flight frequencies and seat numbers and even stopped serving various routes in Spain. According to the figures reported here, HSR has been unable to offset these losses and is incapable of generating enough new traffic.

Indeed, the amount of traffic actually induced by the introduction of HSR services has been much lower than forecast. By way of illustration, $50 \%$ of the traffic on the Madrid-Seville route (de Rus and Inglada, 1997) and $20 \%$ on the Madrid-Barcelona route (Coto-Millán et al., 2007) were expected to be induced. In practice, however, only 26\% on the Madrid-Seville and 9\% on the Madrid-Barcelona route (PWC, 2010) is induced traffic, with the rest being attributable to mode substitution. These figures are in line with the results reported by Preston (2013) and Givoni and Dobruzskes (2014).

This interpretation is consistent with recent results published by Albalate, Bel and Fageda (2015), who found that airlines reduced both the number of seats and flight frequencies when faced with competition from HSR services in Spain during the period 2002-2010. Similar results were also found for Italy and France, but only on routes with a hub airport at one of their ends. In contrast, the results reported herein show that airports have been consistently net contributors of tourists. This suggests the relationship between tourism and airlines is closer than that between tourism and HSR.

Table 5.

Least squares estimates for the double fixed effects equation. Total number of tourists

\begin{tabular}{|c|c|c|c|c|c|c|c|c|}
\hline \multirow[b]{2}{*}{$\mathrm{D}^{\mathrm{HSR}}$} & \multicolumn{2}{|c|}{ FE with clusters (1) } & \multicolumn{2}{|c|}{ FE with AR-1 (2) } & \multicolumn{2}{|c|}{$\begin{array}{l}\text { FE with instrumental } \\
\text { variables procedure for } \\
\text { airport traffic }(3)\end{array}$} & \multicolumn{2}{|c|}{$\begin{array}{l}\text { FE with gamma } \\
\text { distribution (4) }\end{array}$} \\
\hline & $\begin{array}{c}0.33 \\
(1.11) \\
\end{array}$ & - & $\begin{array}{l}0.042 \\
(0.65) \\
\end{array}$ & - & $\begin{array}{c}0.18 \\
(0.52) \\
\end{array}$ & - & $\begin{array}{c}-0.04 \\
(0.24) \\
\end{array}$ & - \\
\hline HSR_dest & - & $\begin{array}{c}0.24 \\
(0.31) \\
\end{array}$ & - & $\begin{array}{c}0.38 \\
(0.19) *\end{array}$ & - & $\begin{array}{c}0.24 \\
(0.13) *\end{array}$ & - & $\begin{array}{l}-0.08 \\
(0.07)\end{array}$ \\
\hline Population & $\begin{array}{c}1.00 \\
(0.34)^{* * *}\end{array}$ & $\begin{array}{c}0.90 \\
(0.31)^{* * *}\end{array}$ & $\begin{array}{c}0.78 \\
(0.24)^{* * *}\end{array}$ & $\begin{array}{c}0.67 \\
(0.24)^{* * *}\end{array}$ & $\begin{array}{c}0.000012 \\
(3.42 \mathrm{e}-06) * * *\end{array}$ & $\begin{array}{c}0.78 \\
(0.28) * * * \\
\end{array}$ & $\begin{array}{c}0.33 \\
(0.18)^{*}\end{array}$ & $\begin{array}{c}0.34 \\
(0.18)^{*}\end{array}$ \\
\hline Airport_traffic & $\begin{array}{c}0.16 \\
(0.02) * * * \\
\end{array}$ & $\begin{array}{c}0.17 \\
(0.02)^{* * *} \\
\end{array}$ & $\begin{array}{c}0.17 \\
(0.013) * * * \\
\end{array}$ & $\begin{array}{c}0.17 \\
(0.013) * * * \\
\end{array}$ & $\begin{array}{c}0.16 \\
(0.02)^{* * *}\end{array}$ & $\begin{array}{c}0.17 \\
(0.017)^{* * *} \\
\end{array}$ & $\begin{array}{c}0.24 \\
(0.02)^{* * * *} \\
\end{array}$ & $\begin{array}{c}0.24 \\
(0.02)^{* * *}\end{array}$ \\
\hline Unemployment & $\begin{array}{c}0.08 \\
(0.09)\end{array}$ & $\begin{array}{c}0.08 \\
(0.09)\end{array}$ & $\begin{array}{l}0.009 \\
(0.05)\end{array}$ & $\begin{array}{c}0.0099 \\
(0.05)\end{array}$ & $\begin{array}{l}0.067 \\
(0.04)\end{array}$ & $\begin{array}{c}0.09 \\
(0.042)^{* *}\end{array}$ & $\begin{array}{l}-0.008 \\
(0.01)\end{array}$ & $\begin{array}{r}-0.006 \\
(0.01)\end{array}$ \\
\hline Rainfall & $\begin{array}{l}0.00018 \\
(0.0006)\end{array}$ & $\begin{array}{c}0.00025 \\
(0.00064)\end{array}$ & $\begin{array}{r}-0.000062 \\
(0.00066) \\
\end{array}$ & $\begin{array}{c}-0.000036 \\
(0.00065)\end{array}$ & $\begin{array}{c}0.000077 \\
(0.00092)\end{array}$ & $\begin{array}{l}0.00026 \\
(0.0009)\end{array}$ & $\begin{array}{c}0.0003 \\
(0.0003) \\
\end{array}$ & $\begin{array}{c}0.0003 \\
(0.0003) \\
\end{array}$ \\
\hline $\begin{array}{c}\text { Time fixed } \\
\text { effects }\end{array}$ & YES & YES & YES & YES & YES & YES & YES & YES \\
\hline $\begin{array}{c}\mathrm{R}^{2} \\
\text { Test joint } \\
\text { significance } \\
\text { Number of } \\
\text { observations }\end{array}$ & $\begin{array}{c}0.82 \\
91.57 * * *\end{array}$ & $\begin{array}{c}0.82 \\
70.97 * * *\end{array}$ & $\begin{array}{c}0.83 \\
18.7 * * * \\
750\end{array}$ & $\begin{array}{c}0.83 \\
19.14 * * * \\
750\end{array}$ & $\begin{array}{c}0.81 \\
18088.57 * * * \\
750\end{array}$ & $\begin{array}{c}0.83 \\
17997.82 * * * \\
750\end{array}$ & $\begin{array}{c}- \\
4206.84 * * * \\
750\end{array}$ & $\begin{array}{c}-\overline{-} \\
4208.87 * * \\
750\end{array}$ \\
\hline
\end{tabular}

Note: Standard errors in parentheses (Robust to heteroskedasticity) Significance at 1\% (***), 5\% (**), $10 \%(*)$.

The results reported herein are also likely to be affected by the typical profile of the HSR user. HSR services are not cheap but rather attract business users who are more willing to pay for time savings 
(Preston, 2012; Cour des Comptes, 2014). Leisure passengers, by contrast, are more price sensitive and more willing to wait, prioritizing monetary costs over time costs. This could also account for the mix of users found on HSR. In this regard, the competitiveness of HSR in relation to aviation (in short and medium-haul distances) is mainly related with frequency, travel time and comfort. HSR is not necessarily cheaper than air transportation, particularly when HSR compete with low-cost airlines. For instance, Albalate and Bel (2012, p. 106) compared prices between HSR and air transportation for the routes Barcelona-Malaga and Barcelona-Seville in 2010. Their figures indicate that HSR was more expensive in both routes considering minimum, medium and maximum prices. In the case of medium prices, HSR oneway trip price was 117 euros to Malaga and 98 euros to Seville. Those taking an aircraft had to pay (medium prices) only 31 and 48 respectively.

Finally, Table 6 shows the results for the same equations but for a different variable of tourism outcomes. Here, interest is not solely in the number of tourists but in the number of overnight stays as well. Very similar results are found for overnight stays. According to the results in Table 6, HSR does not affect consistently overnight stays in terms of HSR station availability or in terms of destination. The variables for HSR are only statistically significant in the regression that uses the generalized linear model with a gamma distribution. In contrast, airport traffic has a significant positive effect on such tourist outcome regardless the technique used.

Table 6.

Least squares estimates for the double fixed effects equation. Overnights

\begin{tabular}{|c|c|c|c|c|c|c|c|c|}
\hline & \multicolumn{2}{|c|}{ FE with clusters } & \multicolumn{2}{|c|}{ FE with AR } & \multicolumn{2}{|c|}{$\begin{array}{c}\text { FE with instrumental } \\
\text { variables procedure for } \\
\text { airport traffic }\end{array}$} & \multicolumn{2}{|c|}{$\begin{array}{c}\text { GLM with gamma } \\
\text { distribution }\end{array}$} \\
\hline $\mathrm{D}^{\mathrm{HSR}}$ & $\begin{array}{l}-0.57 \\
(4.22)\end{array}$ & - & $\begin{array}{c}0.78 \\
(2.28)\end{array}$ & - & $\begin{array}{l}-1.10 \\
(2.07)\end{array}$ & - & $\begin{array}{c}0.74 \\
(0.23)^{* * *}\end{array}$ & - \\
\hline HSR_dest & - & $\begin{array}{l}-0.05 \\
(1.34) \\
\end{array}$ & - & $\begin{array}{c}0.47 \\
(0.68) \\
\end{array}$ & - & $\begin{array}{l}-0.05 \\
(0.54) \\
\end{array}$ & - & $\begin{array}{c}0.18 \\
(0.006)^{* * * *}\end{array}$ \\
\hline Airport_traffic & $\begin{array}{c}0.30 \\
(0.09) * * *\end{array}$ & $\begin{array}{c}0.30 \\
(0.08) * * *\end{array}$ & $\begin{array}{c}0.65 \\
(0.05)^{* * *}\end{array}$ & $\begin{array}{c}0.65 \\
(0.04)^{* * *}\end{array}$ & $\begin{array}{c}0.15 \\
(0.07)^{* *}\end{array}$ & $\begin{array}{c}0.14 \\
(0.07)^{* *}\end{array}$ & $\begin{array}{c}0.39 \\
(0.03) * * *\end{array}$ & $\begin{array}{c}0.39 \\
(0.03) * * * \\
\end{array}$ \\
\hline Population & $\begin{array}{c}1.43 \\
(0.83)^{*}\end{array}$ & $\begin{array}{c}1.43 \\
(1.04) \\
\end{array}$ & $\begin{array}{c}0.66 \\
(0.86) \\
\end{array}$ & $\begin{array}{c}0.54 \\
(0.88) \\
\end{array}$ & $\begin{array}{c}3.53 \\
(1.13)^{* * *} \\
\end{array}$ & $\begin{array}{c}3.62 \\
(1.15) * * * \\
\end{array}$ & $\begin{array}{c}1.02 \\
(0.19) * * * \\
\end{array}$ & $\begin{array}{c}1.03 \\
(0.20) * * * \\
\end{array}$ \\
\hline Unemployment & $\begin{array}{c}0.41 \\
(0.69) \\
\end{array}$ & $\begin{array}{c}0.41 \\
(0.67) \\
\end{array}$ & $\begin{array}{l}-0.20 \\
(0.18) \\
\end{array}$ & $\begin{array}{c}-0.20 \\
(0.18) \\
\end{array}$ & $\begin{array}{c}0.33 \\
(0.17) * \\
\end{array}$ & $\begin{array}{c}0.31 \\
(0.17)^{*}\end{array}$ & $\begin{array}{c}-0.06 \\
(0.009) * * *\end{array}$ & $\begin{array}{c}-0.05 \\
(0.009) * * *\end{array}$ \\
\hline Rainfall & $\begin{array}{l}-0.003 \\
(0.004)\end{array}$ & $\begin{array}{l}-0.003 \\
(0.004)\end{array}$ & $\begin{array}{l}-0.0023 \\
(0.0022)\end{array}$ & $\begin{array}{l}-0.002 \\
(0.002)\end{array}$ & $\begin{array}{l}-1.10 \\
(2.07)\end{array}$ & $\begin{array}{l}-0.003 \\
(0.003)\end{array}$ & $\begin{array}{c}0.0005 \\
(0.0004)\end{array}$ & $\begin{array}{c}0.0005 \\
(0.0004)\end{array}$ \\
\hline Time fixed effects & YES & YES & YES & YES & YES & YES & YES & YES \\
\hline $\begin{array}{c}\mathrm{R}^{2} \\
\text { Test joint } \\
\text { significance } \\
\text { Number of } \\
\text { observations }\end{array}$ & $\begin{array}{c}0.46 \\
15.58 * * * \\
750\end{array}$ & $\begin{array}{c}0.45 \\
21.92 * * * \\
750\end{array}$ & $\begin{array}{c}0.54 \\
18.47 * * * \\
750\end{array}$ & $\begin{array}{c}0.54 \\
18.50 * * * \\
750\end{array}$ & $\begin{array}{c}0.29 \\
12521.18 * * * \\
750\end{array}$ & $\begin{array}{c}0.28 \\
12501.60 * * * \\
750\end{array}$ & $\begin{array}{c}- \\
14684.68 * * * \\
750\end{array}$ & $\begin{array}{c}- \\
14627.94 * * * \\
750\end{array}$ \\
\hline
\end{tabular}




\section{Concluding remarks}

Little is known about the relationship between HSR and tourism, although new transport infrastructure is commonly believed to have positive impacts on the tourist areas it serves. However, this paper has not found consistent evidence in favor of a positive relationship between HSR and tourist outcomes.

Indeed, it appears that HSR has failed to promote tourism in the areas (provinces) receiving new HSR lines. We do not find a relevant direct effect of HSR on tourism. In contrast, we find that HSR has undermined the most important mode of transportation for tourism, namely the airlines.

HSR seems to have a detrimental impact on air traffic so that HSR is more competitive than air travel. However, HSR may be more competitive in terms of frequencies, travel time and comfort and not necessarily in terms of price. Given that travelers for tourism are more sensitive to price than to time, the overall competitiveness of HSR in relation to aviation may not have a positive effect on tourist outcomes.

Our analysis provides empirical evidence about the impact of two recent innovations in transportation on tourism outcomes. While the technological innovation that HSR represents does not have a strong influence on tourism, the managerial innovation that implies the low-cost airline business model seem to have a more consistent effect on tourist outcomes.

In short, this paper highlights the importance of intermodal interactions and the pressing need to develop integrated transportation plans. Note here that a limitation of our empirical analysis is that we do not have available data for rail traffic and prices at the province level. A project for future research is to quantify empirically the impact of HSR on traffic of other transportation modes, particularly air transportation. This would allow us to deepen the study of the relationship between HSR and tourism.

Interestingly, the paper's findings illustrate that at times more can in fact mean less. Augmenting the supply of transportation with additional modes may not have positive effects on economic activities when the mode that loses out is air transportation. Although further research is required to understand fully the impact of HSR on mobility and, particularly, on tourism, this paper provides a more skeptical view of HSR development projects, which are usually initiated with great enthusiasm and optimism, also from the tourism industry. This paper's conclusions, therefore, are very much in line with the findings from the expost literature that point to the potentially disappointing impact of HSR developments.

\section{Acknowledgements}

This study received support from the Spanish Government - project ECO2012-38004 - and from the Regional Government of Catalonia - project SGR2014-325. 


\section{References}

Abeyratne, R. 1993. Air transport tax and its consequences on tourism, Annals of Tourism Research, 20: $450-460$.

Albalate, D.; Bel, G. 2010. Tourism and urban public transport: Holding demand pressure under supply constraints, Tourism Management, 31: 425-433.

Albalate, D., Bel, G. 2012. The economics and politics of high-speed rail. Lessons from experiences abroad. Rowman and Littlefield Publishers (Lexington Books), Lanham, MA.

Albalate, D.; Bel, G., Fageda, X. 2015. When supply travels far beyond demand: Institutional and regulatory causes of oversupply in Spain's transport infrastructure, Transport Policy 41, 80-89.

Albalate, D.; Bel, G., Fageda, X. 2015. Competition and Cooperation between High Speed Rail and Air Transportation Services in Europe, Journal of Transport Geography, forthcoming.

Alegre, J.; Mateo, S., Pou, Ll. 2013. Tourism participation and expenditure by Spanish households: The effects of the economic crisis and unemployment, Tourism Management, 39: 37-49.

Antes, J.; Friebel, G., Niffka, M.; Rompf, D., 2004. Entry of low-cost airlines in Germany: some lessons for the economics of railroads and intermodal competition. Second Conference on railroad industry Structure, Competition and Investment, Northwestern University, Evanston (IL).

Bazin, S.; Beckerich, C., Delaplace, M. (2006) "Analyse prospective des impacts de la Ligne à Grande Vitesse Est-européenne dans l'agglomération rémoise et en région Champagne-Ardenne", Report final de recherché pour le Conseil Régional Champagne-Ardenne, Université de Reims ChampagneArdenne.

Bazin, Sylvi, Beckerich, C.; Delaplace, M. 2010. Grande vitesse, activation des ressources spécifiques et développement du tourisme urbain : le cas de l'agglomération rémoise, Belgeo 1-2 : 65-78

Bazin, S.; Beckerich, C.; Delaplace, M. 2013. Desserte TGV et villes petites et moyennes, Une illustration par le cas du tourisme à Arras, Auray, Charleville-Mézières et Saverne, Les Cahiers Scientifiques du Transport $63: 33-62$

Behrens, C.; Pels, E., 2012. Intermodal competition in The London-Paris Passenger Market: High-Speed Rail and Air Transport, Journal of Urban Economics, 71(3): 278-288.

Bel, G. 2011. Infrastructure and nation building: the regulation and financing of network transport infrastructures in Spain (1720-2010), Business History, 53(5): 688-705.

Bel, G. (2012) Infrastructure and the Political Economy of Nation Building in Spain, 1720-2010. Eastbourne: Sussex Academic Press

Bertrand, M.; Duflo, E.; Mullainathan, S. 2004. How much should we trust differences-in-differences estimates?, The Quarterly Journal of Economics, 119: 249-275.

Bieger, T., Wittmer, A., 2006. Air transport and tourism - perspectives and challenges for destinations, airlines and governments. Journal of Air Transport Management 12, 40-46.

Bonnafous, A. 1987. The Regional Impact of the TGV. Transportation 14(2): 127-137.

Bramwell, B.; Lane, B. 2009. Economic cycles, times of change, and sustainable tourism, Journal of Sustainable Tourism, 17(1): 1-4.

Cascetta, E.; Papola, A.; Pagliara, F.; Marzano, V. 2011. Analysis of mobility impacts of the high speed Rome-Naples rail link using within day dynamic mode service choice models, Journal of Transport Geography 19(4): 635-643.

Clever, R.; Hansen, M. 2008. Interaction of air and high-speed rail in Japan, Transportation Research Record 2043: 1-12

Cheng, Y.H. 2010. High-Speed Rail in Taiwan: New Experience and Issues for Future Development, Transport Policy 17: 51-63.

Chen, Z.; Haynes, K. 2012. Tourism Industry and High Speed Rail, Is There a Linkage: Evidence from China's High Speed Rail Development. ASRDLF 2012 conference special session on High Speed Rail, Tourism and Territories, $9^{\text {th }}-11^{\text {th }}$ July, Belfort, France.

Chen, Z., Haynes, K. 2015. Impact of high-speed rail on international tourism demand in China, Applied Economic Letters 22(1): 57-60.

Cheng, Y-H. 2009. High-speed rail in Taiwan: New experience and issues for future development, Transport policy 17(2): 51-63

Chew, J. (1987) Transport and tourism in the year 2000. Tourism Management, 8(2): 83-85.

Clever, R.; Hansen, M. 2008. Interaction of air and high speed rail in Japan, Transportation Research Record: Journal of the Transportation Research Board 2043, 1-12.

Clewlow, R.R.; Sussman, J.M.; Balakrishnan, H. 2012. Interaction of high-speed rail and aviation, Transportation Research Record 2266(1): 1-10.

Coto-Millán, P.; Inglada, V.; Rey, B. 2007. Effects of network economies in high-speed rail: the Spanish case, Annals of Regional Science 41: 911-925. 
Chung J.Y; Whang T. 2011. The impact of low cost carriers on Korean Island tourism. Journal of Transport Geography 19: 1335-1340.

Cour des Comptes. 2014. La grande vitesse ferroviaire: un modèle porté au-delà de sa pertinence. París: Cour des Comptes.

Day, J.; Chin, N.; Sydnor, S.; Cherkauer, K. 2013. Weather, climate, and tourism performance: A quantitative analysis, Tourism Management Perspectives 5: 51-56.

De Rus, G.; Inglada, V. 1997. Cost-benefit analysis of the high-speed train in Spain. Annals of Regional Science 31:175-188.

Delaplace, M. 2012. TGV, développement local et taille des villes; Une analyse en termes d'innovation de services, Revue d'économie régionale et urbaine 2: 265-292

Delaplace, M.; Perrin, J. (2013) Multiplication des dessertes TGV et Tourismes urbains et d'affaires, Regards croisés sur la Province et l'Ile de France, Recherche Transport et Sécurité 29:177-191

Delaplace, M., Pagliara, F., Perrin, J., Mermet, S. 2014. Can High Speed Rail foster the choice of destination for tourism purpose? EWGT2013 - 16th Meeting of the EURO Working Group on Transportation,Procedia - Social and Behavioral Sciences, 111: 166 - 175

Della Corte, V.; Sciarelli, M.; Cascella, C.; Del Gaudio, G. 2013. Customer Satisfaction in Tourist Destination: The Case of Tourism Offer in the City of Naples. Journal of Investment and Management. Special Issue: Attractiveness and Governance of Tourist Destinations 4(1-1): 39-50.

Dobruszkes, F., 2011. High-Speed Rail and Air Transport Competition in Western Europe: A SupplyOriented Perspective, Transport Policy 18: 870-879.

Dobruszkes, F., Mondou, V., 2013. Aviation liberalization as a means to promote international tourism: the EU-Morocco case. Journal of Air Transport Management, 29:23-34.

Dobruszkes, F.; Dehon, C.; Givoni, M. 2014. "Does European high-speed rail affect the current level of air services? An EU-wide analysis", Transportation research Part A 69, 461-475.

Donzelli M., 2010. The effect of low-cost air transportation on the local economy evidence from Southern Italy. Journal of Air Transport Management 16: 121-126.

Edwards, N. 2012. High Speed Rail benefits that add up, report for the Australian Greens.

Ellwanger,G.; Wilckens, M. 1993. Hochgeschwindigkeitsverkehr gewinnt an Fahrt (High-speed traffic booms). Internationales Verkehrswesen 45 (5), 284-290.

European Commission, 1996. Interaction between High Speed and Air Passenger Transport - Interim Report. Interim Report on the Action COST 318, April. Brussels.

Feliu J. 2012. High-Speed Rail in European Medium-Sized Cities: Stakeholders and Urban Development, Journal of urban planning and development 138: 293-302.

Fu X.; Oum T.H.; Yan J. 2014. An analysis of travel demand in Japan's inter-city market: empirical estimation and policy simulation. Journal of Transport Economics and Policy 48(1): 97-113.

Fu, X.; Zhang, A.; Lei, Z. 2012. Will China's airline industry survive the entry of high-speed rail? Research in Transport Economics 35(1): 13-25.

Gibb, R. 1986. The impact of the Channel Tunnel rail link on South East England, The geographical journal $152, \mathrm{n}^{\circ} 3$.

Givoni, M.; Banister, D., 2006. Airline and railway integration. Transport Policy, 13: 386-397.

Givoni, M.; Dobruszkes, F. 2014. A Review of Ex-Post Evidence for Mode Substitution and Induced Demand Following the Introduction of High-Speed Rail, Transport Reviews 33(6): 720-742.

Gómez, M.B. 2005. "Weather, climate and tourism a geographical perspective, Annals of Tourism Research, 32(3): 571-591.

González-Savignat, M. 2004. Competition in air transport. The case of the high speed train, Journal of Transport Economics and Policy 38(1): 77-108.

Grimme, W. 2006. Air/rail intermodality recent experiences from Germany, Airlines Magazine 34: 1-4.

Guizzardi, A., Mazzocchi, M. 2010. Tourism demand for Italy and the business cycle, Tourism Management, 31(3): 367-377.

Hall, D.R. 1999. Conceptualising tourism transport: inequality and externality issues, Journal of Transport Geography 7(3):181-188.

Janic, M., 1993. A model of competition between high speed rail and air transport. Transportation Planning and Technology, 17(1): 1-23.

Jiménez, J.L.; Betancor, O. 2012. When trains go faster than planes: the strategic reaction of airlines in Spain, Transport Policy, 23: 34-41.

Kappes, J.W.; Merkert, R. 2013. Barriers to entry into European aviation markets revisited: a review and analysis of managerial perceptions, Transportation Research Part E 57: 58-69

Khadaroo, J.; Seetanah, B. 2007. Transport infrastructure and tourism development, Annals of Tourism Research 34(4), 1021-1032. 
Khadaroo, J.; Seetanah, B. 2008. The role of transport infrastructure in international tourism development: A gravity model approach, Tourism Management, 29(5): 831-840.

Klein, O. 1997. Le TGV-Atlantique et les évolutions de la mobilité: entre crise et concurrence. Les Cahiers Scientifiques des Transports 32: 57-83.

Klein, O.; Claisse, G. 1997. Le TGV-Atlantique: entre récession et cencurrence. Evolution de la mobilité et mise en service du TGV-Atlantique: analyse des enquêtes réalisées en septiembre 1989 et septiembre 1993. Lyon: Laboratoire d'Economie des Transports, 1997.

Lee, J.-K.; Yoo, K.E.; Jung, S.-Y. 2012. A Study on the Effect of High-speed Railway Launch to the Air Passengers' Mode Choice Behaviour, Paper presented at the 16th ATRS World Conference, Tainan, Taiwan, June 2012.

Lise, W.; Tol, R. 2002. Impact of climate on tourist demand, Climatic change, 55: 429-449.

Martín, J.C.; Nombela, G. 2008. Microeconomic impacts of investments in high speed trains in Spain, Annals of Regional Science, 41:715-733

Martin, C.A.; Witt, S.F. 1988. Substitute prices in models of tourism demand, Annals of Tourism Research, 15: 255-268.

Masson, S.; Petiot, R. 2009. Can the high speed rail reinforce tourism attractiveness ? The case of the high speed rail between Perpignan (France) and Barcelona (Spain), Technovation, 29(9): 611-617.

Murakami, J.; Cervero, R. 2012. High-Speed Rail and Economic Development: Business Agglomerations and Policy Implications, UC Berkeley University of California Transportation Center UCTC.

Okabe, S. 1979. Impact of the Sanyo Shinkansen on Local Communities." In The Shinkansen High-Speed Rail Network of Japan (proceedings of an International Institute for Applied Systems Analysis Conference, June 27-30, 1977), A. Straszak, and R. Tuch, eds.: 105-129.

Pagliara, F.; Vassallo, J.M.; Roman, C. 2012. High-speed rail versus air transportation. Case study of Madrid-Barcelona, Spain, Transportation Research Record, 2289:10-17

Pagliara, F., La Pietra, A., Gomez, J., Vassallo, J.M. 2015. High speed rail and the tourism market: Evidence from the Madrid case study", Transport Policy 37: 187-194.

Peeters, P.; Szimba, E.; Duijnisveld, M. 2007. Major environmental impacts of European tourist transport, Journal of Transport Geography, 15(2): 83-93.

Preston, J. 2012. High-speed rail in Britain: about time or a waste of time?, Journal of Transport Geography, 22, 308-311.

Preston, J. 2013. The Economics of Investment in High Speed Rail: Summary and Conclusions. OECD, International Transport Forum, Discussion paper 2013-30.

Prideaux, B. 2000. The role of the transport system in destination development, Tourism Management, 21: $53-63$.

PWC (2010). Impacto socioeconómico del AVE a Valencia. Valencia: Generalitat Valenciana. (In Spanish).

Rey, B., Myro, R., Galera, A. 2011. Effect of low-cost airlines on tourism in Spain. A dynamic panel data model. Journal of Air Transport Management 17:163-167.

Riietveld, P.; Bruinsma, F.; Van Delft, H.; Ubbels, B. (2001) Economic impacts of high speed trains. Experiences in Japan and France: expectations in The Netherlands, Serie Research Memoranda (de Faculteit der Economische Wetenschappen en Bedrijfskunde), $\mathrm{n}^{\circ} 20$

Román, C.; Espino, R.; Martín. J.C. 2007. Competition of high-speed train with air transport: the case of Madrid-Barcelona, Journal of Air Transport Management, 13: 277-284.

Román, C.; Espino, R.; Martín. J.C. 2010. Analyzing Competition between the High Speed Train and Alternative Modes. The Case of the Madrid-Zaragoza-Barcelona Corridor, Journal of Choice modeling 3(1): 84-108

Scuttari, A., Della Lucia, M. Martini, U., 2013. Integrated planning for sustainable tourism and mobility. A tourism traffic analysis in Italy's South Tyrol region. Journal of Sustainable Tourism 21, 614-637.

Seetanah, B., Khadaroo, J. 2009. An analysis of the relationship between transport capital and tourism development in a dynamic framework, Tourism Economics 15, 785-802).

South east England Development Agency (SEEDA). 2008. HST Impact Study, Final report pour la Commission européenne, http://www.hstimpactstudy.net/HTdocs/ Images/mainreport 150408.pdf.

Steer Davies Gleave (2006) Air and rail competition and complementarity Final report for the European Commission (DG TREN), Steer Davies Gleave, London.

Suh, S.; Keun-yul Y.; Jeon Hyun, K., 2005. Effects of Korean Train Express (KTX) Operation on the National Transport System, Proceedings of the Eastern Asia Society for Transportation Studies 5: 175-189.

Taniguchi, M. 1992. High Speed Rail in Japan: A Review and Evaluation of the Shinkansen Train. University of California Working Paper UCTC, no. 103. 
Vickerman, R. 1997. High-speed rail in Europe: Experience and issues for future development, The Annals of Regional Science, 31: 21-38.

Vowles, T. M. 2001. The "Southwest Effect" in multi-airport regions, Journal of Air Transport Management, 7: 251-258.

Wu, Jianghong. 2013. The Financial and Economic Assessment of China's High Speed Rail Investments: a Preliminary Analysis. Discussion Paper, International Transport Forum, Paris.

Wang X.; Huang, S.; Zou, T.; Yan, H. 2012. Effects of the high speed rail network on China's regional tourism development, Tourism Management Perspectives 1: 34-38

Zhang, Q.; Yang, H.; Wang, Q.; Zhang, A. 2014. Market power and its determinants in the Chinese airline industry, Transportation Research Part A: Policy and Practice, 64: 1-13.

Appendix

Table A1. List of low-cost airlines offering flights in Spanish airports

Air Arabia Maroc, Air Berlin, Air Finland, Air One, Alpi Eagles, Blue Air, bmi baby, Britannia Airways, Cai Second, Centralwings, Clickair, Condor, dba, easyjet, Eurowings, First Choice, Fly Me, FlyNordic, Germanwings, Hapagfly, Jet2, Jet4you, LTU, Monarch, MyAir, MyTravelLite, NIKI, Norwegian, Pegasus, Ryanair, SkyEurope, Smart Wings, Sterling, Thomson, Thomas Cook, Transavia, TUIFly, Virgin Express, Volare, Vueling, Wind Jet, Wizzair 